\title{
To study pattern of obstetric cases referred at tertiary care centre in Central India
}

\author{
Prakriti Goswami*, Jyoti Bindal, Niketa Chug
}

Department of Obstetrics and Gynecology, G. R. Medical College, Gwalior, Madhya Pradesh, India

Received: 06 March 2017

Accepted: 07 April 2017

\section{*Correspondence:}

Dr. Prakriti Goswami,

E-mail: goswami.prakriti@gmail.com

Copyright: $\odot$ the author(s), publisher and licensee Medip Academy. This is an open-access article distributed under the terms of the Creative Commons Attribution Non-Commercial License, which permits unrestricted non-commercial use, distribution, and reproduction in any medium, provided the original work is properly cited.

\begin{abstract}
Background: Maternal morbidity and mortality remains a major challenge to health systems worldwide. Referral services for identification and referral of high risk pregnancies are an integral part of maternal and child health services. Timeliness and appropriateness of referral are challenge to obstetricians, since delay in referral affects maternal outcome adversely, hence the identification of at risk patients and obstetric emergencies and their timely referral is of immense importance. The aim of this study was to review the pattern of obstetric cases referred to tertiary care centre, to identify their clinical course, mode of delivery and maternal outcomes.

Methods: It was prospective observational study carried out from January 2015 to July 2016. Study population was all Obstetrics patients referred to Department of Obstetrics and Gynecology of Kamla Raja Hospital, G.R. Medical College, Gwalior, Madhya Pradesh, a tertiary care centre during the study period.

Results: The total number of referred cases in above study period was 4085 . The proportion of referred cases in the tertiary care hospital was $20.86 \%$. Mode of transport used by the referred patients were hospital ambulances (38\%) and private vehicles (62\%). Most common diagnosis at the time of referral was anaemia $(27.8 \%)$. Out of the total referred cases, $48 \%$ had vaginal delivery (either spontaneous or induced), $28 \%$ had caesarean section and $24 \%$ were managed conservatively. Hypertensive disorders $(25.4 \%)$ constitutes the leading cause of maternal deaths amongst the referred cases.

Conclusions: Peripheral health care system needs to be strengthened and practice of early referral needs to be implemented for better maternal outcome.
\end{abstract}

Keywords: Maternal morbidity and mortality, Maternal outcome, Obstetrics referrals

\section{INTRODUCTION}

Referral services for identification and referral of high risk pregnancies are an integral part of maternal and child health services. For a large majority of developing countries this aspect of health system remains weak. ${ }^{1}$

The 3-tier health care delivery system was conceived in such a manner that the patients in need of a higher level of expertise and care could be referred accordingly from primary to secondary directly to tertiary level centre. The
Prevention of Maternal Mortality (PMM) network study has proposed a three delays model for referrals in obstetric and gynaecological emergencies. ${ }^{2}$ A study showed that $92 \%$ of maternal deaths are due to delay in referral and case management, first delay in making decision to seek care, $2^{\text {nd }}$ delay is due to delay in identifying and reaching a medical facility, 3rd delay is due to delay in receiving adequate and prompt treatment even after reaching a care institution. ${ }^{3,4}$ Although most obstetric complications (defined as acute conditions such as postpartum haemorrhage, sepsis, eclampsia, and 
obstructed labour that can cause maternal death cannot be predicted, the majority can be treated with timely provision of a package of evidence-based interventions known as emergency obstetric care (EmOC). ${ }^{5-7}$

The availability of EmOC is considered to be an indicator of how well a health system is prepared to manage conditions leading to acute maternal morbidity and mortality. ${ }^{8,9}$

Emergency obstetric care EmOC refers to elements of obstetric care needed or management of complications during pregnancy, delivery and postpartum period, skilled personnel, equipment and support services. EmOC services are of paramount importance in reducing maternal mortality and morbidity. It is still recommended to electively refer pregnant woman with previous caesarean section, breech presentation, transverse lie, multiple gestation, hypertension and severe anaemia for delivery before any complication arise to a health care centre where all the facilities to deal with the complications are available. With this background, present study was undertaken to evaluate the pattern of obstetric cases referred to tertiary teaching hospital and maternal outcomes amongst referred patients.

\section{METHODS}

Study design: Prospective observational study. Study period: January 2015 to July 2016. Study population: All Obstetrics cases referred to the Department of Obstetrics and Gynecology of Kamla Raja Hospital, G.R. Medical College, Gwalior, M.P., a tertiary care centre during the study period.

\section{Data collection}

The study data was collected from case sheets of the patients referred and managed at tertiary teaching hospital. Detailed clinical history, place of referral, type of transport used, causes of referral were studied. Complete physical and obstetric examination was done and relevant investigations were done. Management of the patient, clinical course, mode of delivery (i.e., whether vaginal or operative) and maternal outcome was documented. Descriptive statistics like percentages were used for analysis.

\section{RESULTS}

4085 obstetric cases were referred to the Department of Obstetrics and Gynaecology, Kamla Raja hospital, G.R. Medical College, Gwalior, M.P. during the study period. Total number of Obstetrics admissions during the study period was 19,577. The proportion of referred cases of the total obstetric admissions in our study was $20.86 \%$.

Maximum number of cases in the present study were in the age group 20-30yrs, comprising $78 \%$ of total cases (Table 1).
Table 1: Distribution of cases according to age.

\begin{tabular}{|lll|}
\hline Age (yrs) & Number of cases & $\%$ \\
\hline$<20$ & 572 & 14 \\
\hline $20-30$ & 3186 & 78 \\
\hline$>30$ & 327 & 8 \\
\hline
\end{tabular}

Majority (47\%) of cases in our study were primigravidae (Table 2).

Table 2: Distribution of cases according to parity.

\begin{tabular}{|lll|}
\hline Parity & Number of cases & $\%$ \\
\hline Primi & 1920 & 47 \\
\hline Multi & 1757 & 43.01 \\
\hline Grand multi & 408 & 9.99 \\
\hline
\end{tabular}

$56 \%$ of cases in our study were referred in the intra partum period to our hospital (Figure 1).

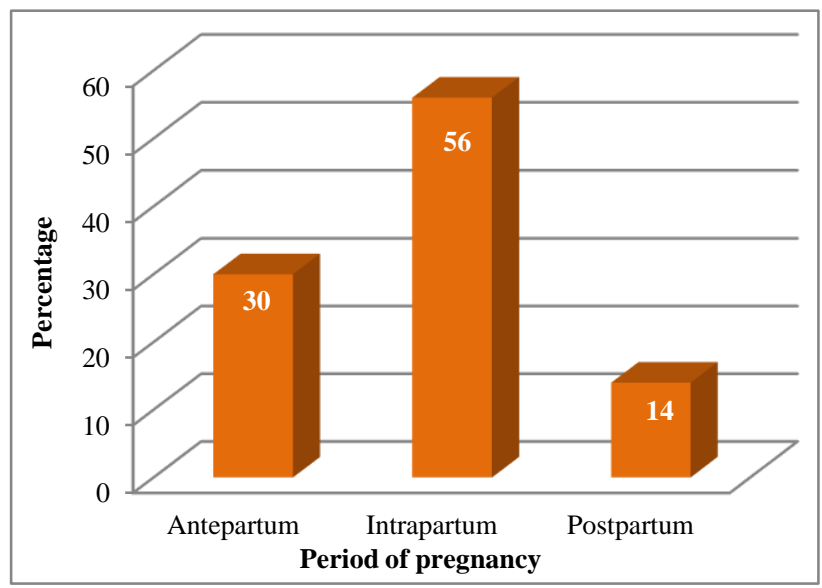

Figure 1: Distribution of cases according to period of pregnancy.

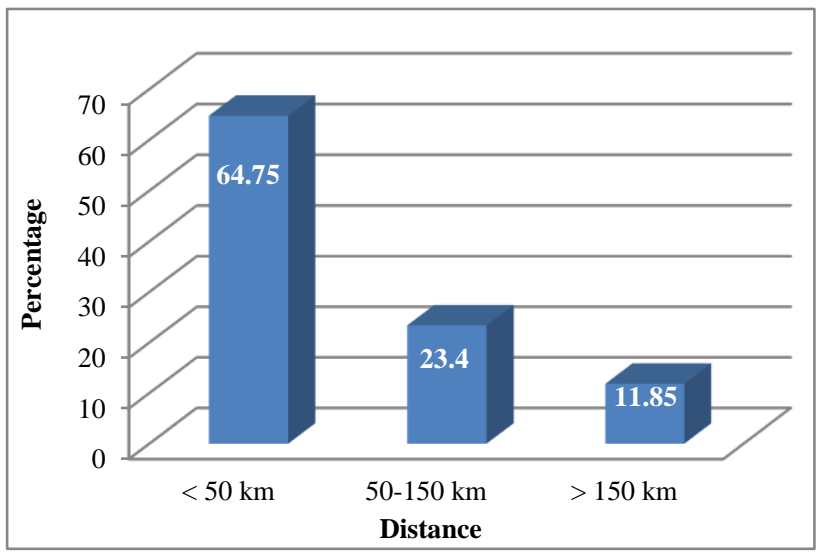

Figure 2: Distribution of cases according to distance from the referral centre.

$64.75 \%$ of cases were referred to our hospital from $<50$ $\mathrm{km}$ distance (Figure 2). Mode of transport used by the referred patients were hospital ambulances $(38 \%)$ and private vehicles (62\%) (Figure 3). 


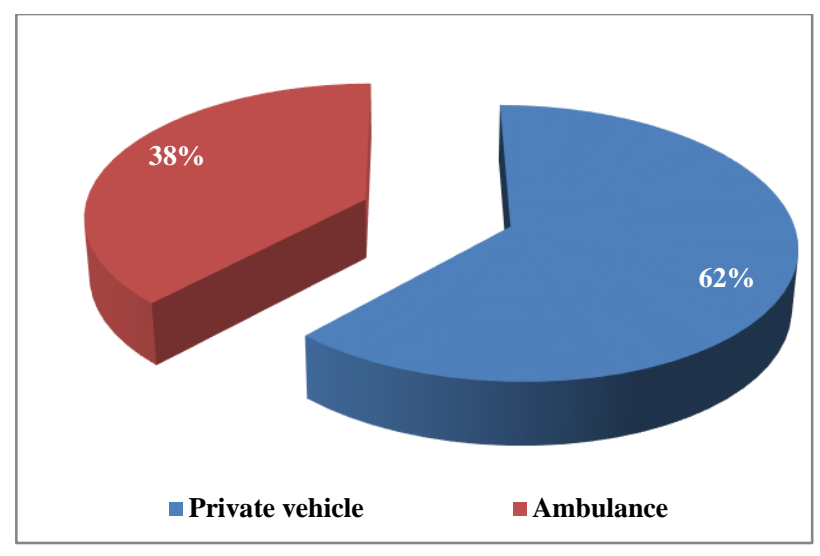

Figure 3: Mode of transport used.

Anaemia (27.86\%) followed by hypertensive disorders of pregnancy $(17 \%)$ were the major causes of referral to the tertiary care centre. $16.87 \%$ of cases were referred for lack of functional Operation Theatres, Blood banks and gynaecologists, competent enough for doing caesarean section (Figure 4).

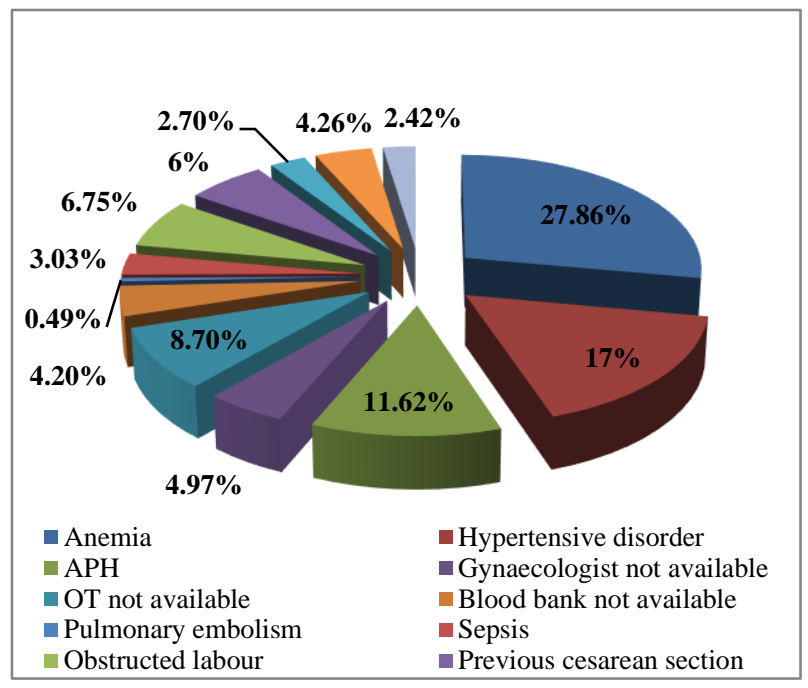

Figure 4: Causes of referral.

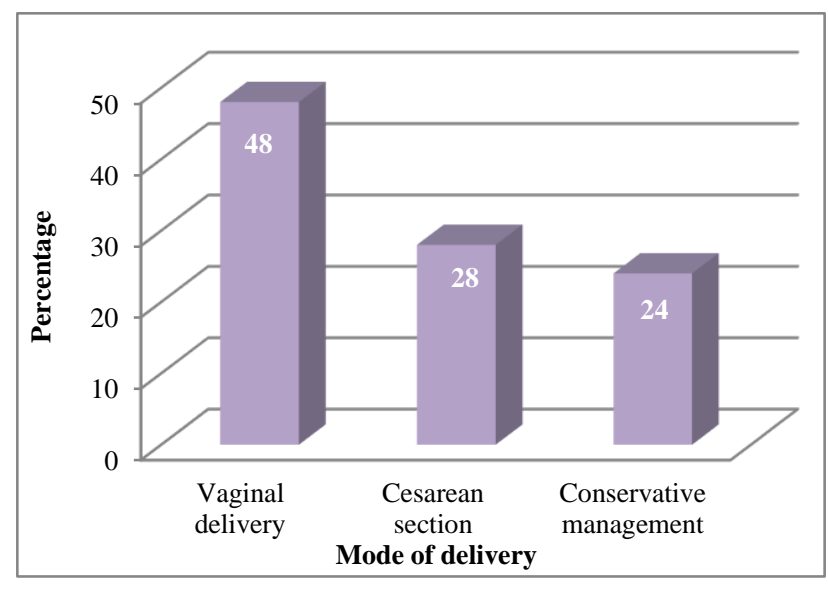

Figure 5: Distribution of cases according to mode of delivery.
Out of the total referred cases, $48 \%$ had vaginal delivery (either spontaneous or induced), 28\% had caesarean section and $24 \%$ were managed conservatively (Figure $5)$. The commonest indication of caesarean section amongst referred patients in our study was fetal distress. Obstetric ICU admission was required in 545 out of 4085 referred cases i.e. in $13.34 \%$ of referred cases. Total 163 maternal deaths were reported during the study period, of which 84 (i.e. 51.53\%) were referred from various peripheral centres. Hypertensive disorders (25.4\%) constitute the leading cause of maternal deaths amongst the referred cases.

\section{DISCUSSION}

Kamla raja hospital is a tertiary care hospital attached to Gajra Raja Medical College, Gwalior, M.P., India, where complicated obstetrics and gynaecological cases are referred from various peripheral primary health centres and private hospitals of surrounding districts, catering to a total area of nearly $300 \mathrm{kms}$.

The World Health Organization estimates that at least 88$98 \%$ of maternal deaths can be averted with timely access to existing, emergency obstetric care using effective and efficient referral systems. ${ }^{10}$ Timeliness and appropriateness of referral are a challenge to obstetricians, since the delay in referral affects the maternal and perinatal outcome adversely, hence identification of "at risk" patients and obstetric emergencies and timely referral is of immense importance. Puri Alka et al in their study noted $24.16 \%$ of cases were referred. ${ }^{11}$ The proportion of referred cases at our tertiary care centre was $20.86 \%$.

Morsheda Banu et al on assessing the overall age distribution found that majority $(74 \%)$ of the respondents were between $20-35$ years. ${ }^{12}$ In the present study, also the maximum number of patients $(78 \%)$ were in the $20-30$ years of age group.

Gupta PR et al found $52.17 \%$ patients were primigravida, which is comparable to $47 \%$ primigravida cases found in our study. ${ }^{13} 56 \%, 30 \%$ and $14 \%$ of cases were referred to our hospital in their intrapartum, antepartum and postpartum period respectively. Similar results were found by Devineni K et al ${ }^{14}$ in their "Study of spectrum of referral pattern at a tertiary teaching hospital towards better obstetric care". Sakhare A.P. et al observed that $65 \%$ cases travelled more than $50 \mathrm{~km}$ distance before reaching to hospital and had increased incidence of intra operative complications and hemorrhage. ${ }^{15}$ In present study, $64.75 \%$ cases were referred from within $50 \mathrm{~km}$ distance, $23.4 \%$ cases travelled $50-150 \mathrm{~km}$ distance before reaching the hospital and $11.85 \%$ case travelled more than $150 \mathrm{~km}$ distance before reaching our hospital.

In a study conducted by Narwadkar Mangesh Vinayak et al, only $11 \%$ patients travelled by ambulance. ${ }^{16}$ In present study, $38 \%$ of patients travelled by hospital ambulances, 
rest $62 \%$ patients used their private vehicles. Arranging a private vehicle when faced with obstetric emergency necessitating referral takes time and costs money.

Patel HC et al, in their study found that causes of referral were preeclampsia (16\%), MSL (5\%). ${ }^{17}$ In present study, however, Anaemia $(27.86 \%)$ followed by hypertensive disorders of pregnancy $(17 \%)$ were the major causes of referral to the tertiary care hospital. Poor nutritional status and inadequate spacing of pregnancy compounded by inability of poor patients to have adequate diet due to economic reasons leads to high rate of anaemia in pregnancy. Unavailability of blood transfusion facilities in case of severe anaemia at PHC's and CHC's may also contribute to such high percentage of patients being referred to our tertiary care hospitals.

In present study, $16.87 \%$ of cases were referred for unavailability of OT's, Blood banks and gynaecologists competent enough for doing caesarean section. Government should take measures to improve health infrastructure facilities, make provisions for developing new blood banks and appoint trained gynaecologists in the peripheries to reduce the burden on tertiary care centres.

Previous caesarean section was the cause of reference in $6 \%$ of cases in our study, which is comparable to the study conducted by Gupta PR et al; while in study conducted by Khatoon A et al, previous caesarean section was the cause of reference in $15 \%$ of cases. ${ }^{13,18}$ The patients with previous caesarean section are referred to higher centres from $\mathrm{PHC} / \mathrm{CHC}$ due to unavailability of operation theatre, gynaecologists, anaesthetics, trained staff or basic infrastructure deficits.

In present study, $48 \%$ referred cases had vaginal delivery (either spontaneous or induced), $28 \%$ had caesarean section and $24 \%$ cases were managed conservatively. The commonest indication of caesarean section amongst referred patients was fetal distress. The caesarean section rates in our study was comparable to the study conducted by Gupta PR et al; while in the study conducted by Divya Goswami et al on 154 cases referred to tertiary care hospital in Garhwal, 67 patients needed surgical intervention. $^{13,19}$ Sorbye et al found that referral status contributed substantially to the increased caesarean section rate, which was $55 \%$ in formally-referred. ${ }^{20}$ In present study, $28 \%$ referred cases underwent caesarean section so we can conclude that rate of caesarean section is substantially high in referred cases.

In present study, Obstetric ICU admission was required in 545 out of 4085 referred cases i.e. in $13.34 \%$ of referred cases. This percentage is lesser then what was found in earlier studies; $19 \%$ requiring ICU management by Maskey S, et al. ${ }^{21}$

Total 163 maternal deaths were reported during the study period, of which 84 cases (i.e. 51.53\%) were referred.
This shows delay in referral of complicated cases from our peripheral health centres, which could be due to lack of adequate transport facilities or trained personnel in $\mathrm{PHC} / \mathrm{CHC}$. Delay in referral is a big contributing factor for adverse maternal outcome. The leading cause of maternal mortality amongst referred cases in our study was hypertensive disorders and their complications $(25.4 \%)$. Similar results were found by Begum $\mathrm{S}$ et al in their study. ${ }^{22}$

\section{CONCLUSION}

Peripheral health care system needs to be strengthened and practice of early referral needs to be implemented for better maternal outcome. Provision of a dedicated ambulance meant solely for transport of referred patients in every area from which patients are referred is desirable. Health education to the community, better antenatal care up to grass root level, emergency intranatal care, availability of services of skilled birth attendants at the time of child birth, well organized first referral centre with better transportation facility, availability of blood round the clock, anaesthetic facilities and availability of specialist in the field of obstetrics at the referral unit will definitely reduce maternal morbidity and mortality.

\section{ACKNOWLEDGMENTS}

Authors would like to thanks colleagues and residents for their support and cooperation.

\section{Funding: No funding sources}

Conflict of interest: None declared

Ethical approval: The study was approved by the Institutional Ethics Committee

\section{REFERENCES}

1. Park K. Textbook of Preventive and Social Medicine $17^{\text {th }}$ ed. Jabalpur. Banarasidas Bhanoj Publishers; 2000:632.

2. Thaddeus S, Maine D. Too far to walk: maternal mortality in context. Social Science and Medicine. 1994;38:1091-1110.

3. Brun JL, Billeaud C, Elleau C, Guyon F, Roux D, Dallay D et al. Maternal transport to the Bordeaux University Hospital: a retrospective study of 263 cases (1996-1998). J Gynecol Obstet Biol Reprod. 2000;29(4):414-22.

4. Swain S, Prakash A. Utilisation of referral services by high risk pregnant population in rural Varanasi. Indian J Matern Child Health. 1992;3(3):74-6.

5. Koblinsky M, Chowdhury ME, Moran AC, Ronsmans C; Maternal morbidity and disability and their consequences: neglected agenda in maternal health. J Health Popul Nutr. 2012;30:124-30.

6. Lee AC, Lawn JE, Cousens S, Kumar V, Osrin D, Bhutta ZA, et al. Linking families and facilities for care at birth: what works to avert intrapartum related deaths? Int J Gynaecol Obstet. 2009;107(1):65-8. 
7. World Health Organization. Monitoring the building blocks of health systems: a handbook of indicators and their measurement strategies. Geneva: WHO; 2010.

8. Travis P, Bennett S, Haines A, Pang T, Bhutta Z, Hyder AA, et al. Overcoming health-systems constraints to achieve the millennium development goals. Lancet. 2004;364:900.

9. Paxton A, Bailey P, Lobis S; The United Nations process indicators for emergency obstetric care: reflections based on a decade of experience. Int $\mathrm{J}$ Gynaecol Obstet. 2006; 95:192-208.

10. WHO. Mother-Baby Package: Implementing Safe Motherhood in countries. 1994. Geneva: WHO/FHE/MSM/94.11.

11. Puri A, Yadav I, Jain N. Maternal Mortality in an Urban Tertiary Care Hospital of North India. J ObstetGynaecol India. 2011; 61(3):280-5.

12. Morsheda B, Shamsun N, Hashima EN; Assessing the MANOSHI Referral System Addressing Delays in Seeking Emergency Obstetric Care in Dhaka's Slums. MANOSHI Working Paper Series ManoshiWP10:1-36 published by ICDDR, B, BRAC. 2010;10.

13. Gupta PR, Chaudhary SN, Gonnade NV. Maternal and fetal outcome in referred patients to tertiary care center.Sch.J.App.Med.Sci. 2016;4(5C):1624-63.

14. Devineni K, Sodumu N. A study of spectrum of referral pattern at a tertiary teaching hospital towards better obstetric care. IAIM. 2016;3(8):193-8.

15. Sakhare AP, Thakare P. Outcome of caesarean delivery in rural obstetric referrals, $51^{\text {st }}$ Conference AICOG; 2008.
16. Vinayak NM, Panditrao SK, Ramkrishna MA Critical study of referrals in Obstetric Emergencies. J Obstet Gynaecol India. 2004;54(3): 258-9.

17. Patel HC, Singh BB, Moitra M, Kantharia SL. Obstetric Referrals: Scenario at a Primary Health Centre in Gujarat. Natl $\mathbf{J}$ Community Med. 2012;3(4):711-4.

18. Khatoon A, Hasny SF, Irshad S, Ansari J. An audit of obstetrics referrals to Abbasi Shaheed Hospital. Pak J Surg. 2011;27(4):304-8.

19. Goswami D, Makhija A. A study of high risk obstretic referrals to tertiary care hospital in Garhwal, Uttarakhand. IJSR. 2015;4(10):1091-5.

20. Sorbye IK, Vangen S, Oneko O, Sundby J, Bergsjo P. BMC Pregnancy and Childbirth. Caesarean section among referred and self-referred birthing women: a cohort study from a tertiary hospital, north eastern Tanzania. 2011;11(55):1-10.

21. Maskey S. Obstetric referrals to a tertiary teaching hospital of Nepal. NJOG. 2015;19(1):52-6.

22. Begum S, Aziz-un-Nisa I. Analysis of maternal mortality in a tertiary care hospital to determine causes and preventable factors. J Ayub Med Coll Abbottabad. 2003;15(2):49-52.

Cite this article as: Goswami P, Bindal J, Chug N. To study pattern of obstetric cases referred at tertiary care centre in central India. Int J Reprod Contracept Obstet Gynecol 2017;6:2370-4. 